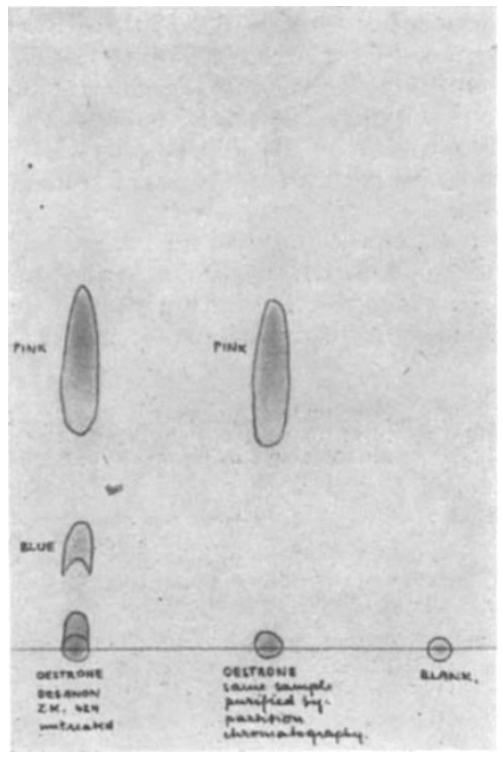

chromatograms, run before and after purification by our technique, showed that the impurity was completely removed by this means (see photograph).

Equilenin, on treatment with 'Fast Black Salt $K$ ', gave a blue spot of similar $R_{F}$ value to that of the impurity, suggesting that the latter consisted of this compound.

This method constitutes a convenient way of purifying small quantities of cestrone, which are recovered quantitatively. A similar technique was used by Haenni ${ }^{3}$ to separate the ostradiols, $\alpha$-dihydroequilin and the dihydroequilenins while this work was in progress.

University College Hospital Medical School,

HanNELORE BraUnSBERG London, W.C.1.

Dec. 18.

${ }^{1}$ Heftmann, E., Science, 111, 571 (1950); J. Amer. Chem. Soc., 73, $851(1951)$.

${ }^{2}$ Swyer. G. I. M., and Braunsberg, H., J. Endocrin., 7, Ix (1951)

${ }^{3}$ Mentioned by Carol, J., $J$ Amer.:Pharm. Assoc., Sci. Ed., 39, 425 (1951).

\section{An Unknown Amino-acid occurring in the Rock Lobster (Jasus Ialandii)}

IN the course of an investigation (to be reported elsewhere) of press liquor, a waste product of the South African rock lobster industry, it was necessary to examine certain nitrogenous fractions. The solute in de-proteinized (trichloroacetic acid) press liquor was found to consist almost entirely of free aminoacids. A phenol/lutidine chromatogram showed an unknown substance giving a pink to pink-purple colour with ninhydrin. From its position on the chromatogram, it could be either methionine sulphoxide, or the ' $T$-spot' ( $\beta$-aminoisobutyric acid) of Crumpler, Dent, Harris and Westall'. The first possibility was disproved by oxidation with hydrogen peroxide in the presence of molybdate; the unknown appearing in its usual position, unlike the sulphoxide, which is oxidized to the sulphone and appears elsewhere on the chromatogram.

Further investigations cast doubt on the second possibility. On a column of cation exchange resin, 'Zeo-Karb 215', the unknown appears with the glycine, alanine and proline fractions, and not between the leucine and histidine fractions, as reported for the ' $T$-spot' by Crumpler et al. Furthermore, it forms a copper complex under the conditions employed by Crumpler and Dent ${ }^{2}$. Taurine and $\gamma$-amino-butyric acid (sample kindly supplied by Dr. C. E. Dent) were used as markers during these experiments, and showed up as clearly on the copper-treated chromatograms as on the untreated ones; any $\alpha$-amino-acids added disappeared after the copper treatment, thus showing the technique to be without fault.

A small quantity of the unknown substance was obtained by preparative paper chromatography and was hydrolysed in a sealed tube with 20 per cent hydrochloric acid for $42 \mathrm{hr}$. at $135^{\circ}$. After this treatment, the unknown still appeared in its usual position on the chromatogram. This precludes the possibility of its being a peptide and raises further doubt as to its identity with $\beta$-aminoisobutyric acid, since the $\beta$-amino-acids are known to be unstable to even mild acid hydrolysis 2 .

It would appear from the evidence given that the unknown substance is not identical with the ' $T$-spot' of Crumpler et al., and this serves to emphasize the care that must be exercised in the interpretation of chromatograms of hitherto uninvestigated materials.

Whether run in neutral or ammoniacal phenol, the substance has the same $R_{F}$ value and therefore would not appear to be basic. The evidence available points to the conclusion that the unknown is a new $\alpha$-aminoacid, possibly a monoamino monocarboxylic acid.

Of the function this acid plays in the rock lobster nothing is known; it may perhaps be a regulator of osmotic pressure ${ }^{3}$.

Isolation of the new acid on a larger scale is in progress with the view of determining its structure.

This communication is published with the permission of the South African Council for Scientific and Industrial Research.

South African Council for Scientific and Industrial Research,

National Chemical Research Laboratory, Pretoria.

March 8.

${ }^{1}$ ('rumpler, H. R., Dent, C. E., Harris, H., and Westall, R. G., Nature, 167, 307 (1951).

2 Crumpler, H. R., and Dent, C. E., Nature, 164, 441 (1949).

${ }^{3}$ Camien, M. N.., Sarlet, H., Cuchâteau, G., and Florkin, M., J. Biol. Chem., 193, $881(1951)$.

\section{A Crystalline Constituent from Myogen of Carp Muscles}

Electrophoresis of aqueous extracts of minced carp muscles after dialysis against water reveals one main gradient corresponding to $80-90$ per cent of the myogen ${ }^{1}$. After prolonged electrophoresis, this gradient separates into several constituents, the most important having a mobility of $-3 \times 10^{-5} \mathrm{~cm} .2 / \mathrm{volt} / \mathrm{sec}$. (ascending) and $-2.5 \mathrm{~cm} .2 / \mathrm{volt} / \mathrm{sec}$. (descending) in phosphate + sodium chloride, $\mu 0 \cdot 15, p \mathrm{H} 7 \cdot 3$.

We have succeeded in isolating and crystallizing a protein of this mobility by the following method. Fresh minced carp muscles are extracted with 1 volume water at $0^{\circ} \mathrm{C}$. for an hour. After dialysis against water and removal of the precipitate by centrifugation, solid ammonium sulphate is added to the extract up to 40 per cent saturation. The precipitate is discarded and the supernatant is brought to 55 per cent saturation by addition of 